\title{
Changing Our Practices: Resisting Habits as an Approach to Self-Study
}

\author{
Craig Jollymore, Sherry Rose, and Ann Sherman \\ University of New Brunswick \\ Author Note
}

Correspondence concerning this article should be addressed to Ann Sherman.

Email: shermana@unb.ca

\begin{abstract}
Since 2011, we have been working at an independent high school with a small group of teachers interested in studying their own teaching practices in ways that support both their individual and collective learning. The participating educators are engaged and challenged by their personal interests in deepening formative assessment practices while creating pedagogic practices that create classroom relevance for their students and themselves. For this paper, we have chosen to explore the self-study of one teacher's journey, in which he engages in the process of examining his own practices, biases, beliefs, and his changing relationships with students. We set the stage for the individual study by discussing the complexity of the interactions between the university faculty and the independent school educators.
\end{abstract}

Keywords: Self-study; professional development; teacher learning

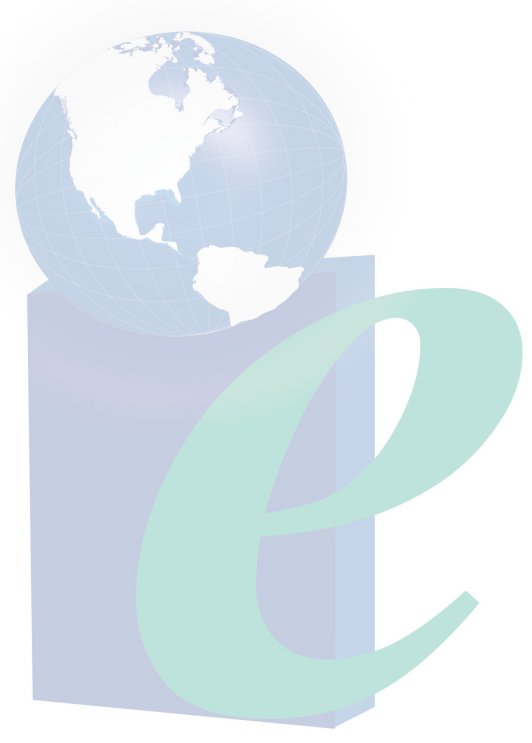




\section{Changing Our Practices: Resisting Habits as an Approach to Self-Study}

\section{Becoming Partners in a Self-Study-Sherry and Ann}

Since 2011, we have been working at an independent high school with a small group of teachers interested in studying their own teaching practices in ways that support both their individual and collective learning. The participating educators are engaged and challenged by their personal interests in deepening formative assessment practices while creating pedagogic practices that create classroom relevance for their students and themselves.

We first met when we were invited to visit the school to support a new professional development strategy the school was implementing. As outside "critical friends" from a nearby university, we were asked to support the evolving focus on professional growth strategies by designing workshops, inviting guest speakers, team teaching in classrooms, providing readings, and engaging with individuals who wanted to delve deeply into their professional practices through self-study. In addition, the School and our Faculty have now co-sponsored three conferences that incorporated both the work done by our Faculty-independent School partnership and the work of many teacher/researchers from regional public school districts.

\section{Informing Our Understanding}

Britzman (2012) reminds us, as teachers, we are often moulded by our own learning experiences in school and if we are to break free of this, we need to find the ways and means to deepen our own ability to think through how habits of practice in the classroom and institutional structures truncate our teaching and students' learning. This team of high school educators have now been involved in four years of cross-institutional collaborations, meetings, conferences, workshops, readings, discussions, and acting as mentors and facilitators. Participants have recorded questions and thoughts in journals and they share regularly with their colleagues and us when we come together. At times, as the "partnering professors," we have "workshop-ed" ideas with the teachers and urged them to challenge themselves in their own classroom practices. Coconstructed workshops were used to create spaces for the voices, stories, and artifacts of students and educators to demythologize the theory/practice divide (Lenz Taguchi, 2007). Several larger group workshops have taken place as well as smaller meetings with the groups of teachers interested in self-study practices.

\section{Using a Framework of Practical Inquiry Through Self-Study}

Self-study is more than an exploration of one's self: "The heart of self-study is the application of the knowledge one gains through this process to one's teaching practices (Samaras, 2002, p. xiv). Some have argued that self-study holds the promise to provide educators with tools that best support teaching and learning. For instance, Pinnegar, et.al. (2010) suggests practical self-inquiry values and challenges teachers in their exploration of contradictory situations, experiences, and stories. As well, Schon's (1983) early notions about reflection-onpractice, or the power of personal theorizing in the development of knowledge about teaching and learning, suggest this reflection is essential as teachers attempt to study their own practices and pedagogies.

Several teachers working with us in this project have taken a particular interest in their own personal growth and are seriously studying their own classroom practices, reading about and attempting real and relevant shifts in their pedagogy. Self-study research engages teachers in this 
investigation of their own practice (Loughran, 2004). The notion of tensions encountered in practice becomes a conceptual frame for doing and understanding one's own practice through self-study (Berry, 2007). A range of critical tensions have continuously occurred in our collective conversations. For example, there are tensions between process and product, summative and formative assessment, student and teachers, assessments and accountability, and the cultivation of critical creativity across all curriculum areas.

We have purposefully constructed our work together to avoid what happens frequently in other forms of professional development. Day (1999) says that too often the lack of change resulting from professional development for teachers is because of large single day conferences. He suggests that there is little evidence to support single day conferences or workshops as a relevant way of making change possible. Instead, Day suggests that there is much that can be done to create the conditions where teacher development and professional growth may be enhanced through conversation and the creation of safe spaces for self-reflection. Wiliam (2011) also calls for authentic professional development that occurs on the floor inside classrooms where our habits of practice can go through significant but modest changes in the interest of learning.

Questioning our habits of personal practice can be difficult. Meaningful inquiry is supported by rich and courageous conversations that engage differences and dissent as productive forces. It was important that these conversations be rooted in a climate of support, collaboration, and respect. Prior to any changes being initiated in this independent school, several formal and informal conversations were held with the educators to develop trust and a commitment to the self-study of their own pedagogy and practices. These teachers are involved in a process of continually re-imagining themselves in the classroom. By asking "what if" questions, change deepens the learning conversations.

Many of our conversations about self-study incorporated ideas around the purpose of self-studies. Craig has participated in discussions and because he is teaching at in an independent school has some flexibility in what curriculum he uses. Therefore, it was important to recognize how both purpose and context can play an important role in his decisions and selections. Loughran (2004) suggests that purpose, participants, and context are all important considerations in self-study and must be examined as any self-study moves forward. Pinar (2006) asserts that often, when we are "distracted by curriculum guides, we risk not seeing what-who is in our midst, and in whose midst we are" (p. xiii); Craig had freedom from such distractions and couldhave an enhanced exploration of context and process within the flexibility of his situation.

In addition, Bullough and Pinnegar (2004) reminded us of the need to look beyond our selves in our self-study and find ways to gain alternative perspectives. The professional growth work we describe here alternates between working alone and whole group discussions around changing pedagogy. As university-based educators, we believe it is important to help educators find ways to look beyond themselves in the process of self-study to better situate themselves in their classroom and context. Looking beyond ourselves occurs when we enter into dialogue with one another, with articles or books, by visiting other schools, and by meeting with invited educators.

Though numerous teachers regularly shared their personal thoughts about professional growth and their own learning, describing what had helped them both initiate and deeply explore 
pedagogical strategies, one of the teachers, Craig, had a particularly strong sense of hesitation and an "It will never work in my classroom...the kids just won't go for it" stance until he made some modest changes that eventually led to greater changes. It is his story that we focus on in this paper

Craig has been teaching for 19 years and regularly teaches English Language Arts to Grades 9 to 12. All of his teaching has been at one independent high school. Out of the intentional collaborations and conversations over the past four years, Craig shares his reflections.

\section{A Problem Years in the Making-Craig's Reflections as Classroom Teacher}

Self-study is the study of one's self, one's actions, one's ideas, as well as the "not self” or the self-becoming. It is autobiographical, historical, cultural, and political and it draws on one's life, but it is more than that. Self-study also involves a thoughtful look at texts read, experiences had, people known and ideas considered. These are investigated for their connections with and relationships to practice as a teacher-educator. (Hamilton, 1996, p. 236)

About five years ago, I (Craig) became aware for the need to change my practice as a teacher. I had been experiencing the way that standardized and externally evaluated curriculum offers the temptation to simply "teach to the test" ( $\mathrm{Au}, 2009$, p. 45). In addition, the International Baccalaureate Literature A1 curriculum, which I have been teaching since 2008, could allow teachers, parents and administrators to define learning simply through student performance on six tasks over two years, something that became a problem, as MacNeil (2005, as cited in Au, 2009, p. 53) pointed out. I had lived Pignatelli's (2005) warning that schooling in these kinds of environments can be "reduced to bottom-line marking and scripted, tightly managed performances on the part of the students” (p. 50).

I had also come to appreciate what a failure the transmission model of teaching was in the study of literature. My experience told me students who could think for themselves always generated better analysis than those who simply remembered what I thought. I was aware of Kellner's (2003) warning that we can "become fixed in mono-modal instruction with homogenized lesson plans, curricula and pedagogy” (p. 15), and Boyce's (1996) call to resist these "coma-like...domesticating uses of education" (p. 12). If I was not careful, student performance could come at the expense of student growth and empowerment. However, knowledge of the problem was not enough to effect change. Working alone made progress difficult. What was I to do about it, on a daily basis, in my practice?

Through our partnership with the university and particularly through my interaction with Ann and Sherry, I was able to develop the vocabulary to describe my concerns and specific strategies for meaningful change in my daily practice. Through this professional relationship, I was exposed to the power of protocols via the National School Reform Faculty and was encouraged to visit progressive schools in Canada and the United States, and, as a result, saw an explosion of social constructivist learning initiatives at our school and in my own practice. Looking back, I can see how carefully Ann and Sherry planned their interactions with us. They took into account exactly where we were as a school and as individual teachers. The progression is now clear: They taught me what it meant to document and collect evidence of my own learning. They made it possible for me to rethink the role of assessment in my practice and, by extension, reimagine the way class time could be used, particularly through personal interactions 
with them and other experts such as Sandra Herbst and Dylan Wiliam. During the process, students' voices began to matter more than mine.

\section{A New Vision of Teaching}

I now see my role as educator to be the creator of conditions for student agency, a direction I can directly attribute to an evening session with Sandra Herbst in the fall of 2013 that was arranged for our Faculty by Ann. Rather than results, I now seek to value the role of process and conceive of learning as creating safe spaces to hear student voices, to encounter each other's thinking, and to facilitate meaning making. I now view learning as a process of opening multiple avenues for growth for all. Davies, Herbst, and Parrot-Reynolds (2012) gave me practical ways to put into action the principle: That all students participate in their assessment and learning and that "classroom assessment strategies provide the means to accomplish...this as teachers and students co-construct criteria for classroom routines, quality work and getting along with one another” (Davies, 2012, p. 15). Herbst's (2014) distinction between assessment and evaluation, and her view that the former involves teachers and students operating side-by-side to exchange feedback and to co-construct criteria that describes quality work has provided me a means to interrupt the power dynamics often present in my classroom when I felt the need to follow standardized assessments.

This has meant that my role has changed; in my best moments, I am now a learning teacher working alongside students who are teaching me. Ann and Sherry have provided the human bridge between the literature and my practice that has made this journey of self-study and changing practice possible. I came to know that Black and Wiliam's (1997, as cited in Davies et al., 2012) research had "shown that involving students in classroom assessment results in considerable gains in achievement, amongst the largest ever reported for educational interventions" (p. ix). But it was the lived experience of Ann and Sherry, combined with the way they interacted with us, that made this promise seem possible in my practice. They modeled the process of self-study leading to changing practices with me.

\section{Student-Generated Novel Studies}

My new approach to learning requires more preparation, more skill, and a concerted effort to abdicate the privileged position my teacher voice possesses. For example, the final fournovel unit in Grade 12 offers the temptation to "teach" the novels. Instead, the unit now consists of co-constructed learning activities that are almost always student-led. These include full class discussions that are mapped, small group discussions, individual choice on how to demonstrate knowledge and understanding, reflection activities, or online collaborative reader response journals. Classes are most often shaped by student-generated questions. My voice has been placed at the margins as students struggle together to construct meaning.

None of these activities mirrors a standardized evaluation but this change in process has led to demonstrably improved results on the externally evaluated International Baccalaureate Paper 2 examination because students are better able to independently express knowledge, understanding, and insight when analyzing complex texts. I am often stunned at what I learn in student-led discussions about complex texts that I have taught for many years. I also have to wait my turn to have my voice heard. Our classroom culture now demands this. What an important self-learning this has been for me. 


\section{Feedback on Student Writing}

Because of Ann and Sherry's specific encouragement, and my own self-study, my own practice has seen significant change. Now I routinely return drafts of student writing with personalized specific feedback, but without a grade. I follow this up with one-on-one meetings. At first, students resisted this because they had been conditioned to think about learning in terms of grades. But the process has yielded increased student growth because of the nature of the feedback. Students are always shown multiple samples of quality work and co-construct criteria for successful work prior to beginning any projects. They are now provided with clear, specific feedback from both peers and me about how to develop their own thinking and ways of documenting their learning. Ann championed the work of Dylan Wiliam to me in connection with the idea that "feedback has been shown to improve learning where it gives each pupils specific guidance on strengths and weaknesses, preferably without any overall marks" (Black \& Wiliam, 1998, p. 144). Timed, in-class writing is also a required part of our course, but students now receive three individualized pieces of feedback in addition to a rubric score. The feedback is formative and I consider student progress in light of the application of specific feedback over time, not on improved rubric scores. These are the practices that I have now been able to incorporate into my classes after recognizing that I also thrive on this very kind of feedback about my own teaching. How much more I have learned by being able to discuss my practice with colleagues and others interested in my work. I now see how this same kind of opportunity benefits my students so much.

Evaluation has become an exercise in professional judgment for assessment rather than arithmetic. I think more broadly about what counts as evidence of learning, and I include student engagement in formative assessment processes alongside results on summative evaluations. I remember going through the report card process with a Grade 9 class. Because I had expanded my definition of what counts as learning (inspired by Ann, Sherry, Sandra Herbst and Dylan Wiliam), I suddenly had more evidence than ever before to consider, much of it captured in easily accessible digital formats. The mark was somehow a much more complete reflection of each student. Although generating those grades took longer, writing comments was a fluid process because I had too much evidence to include for each learner.

\section{Learning Interviews and Classroom Culture}

Recently, after six weeks of classes, I held learning interviews with every student. The process of self-study set in motion by Ann and Sherry inspired this. Each student and I first dealt with the elephant in the room: What grade did they want to earn in the course? But we then moved on to issues actually relevant to learning and growth. What learning activities were most effective for them? Which were least effective? What did they think of the proposed syllabus? Did they have suggestions? How did they want to grow as readers? Writers? Learners? Why? What were their ideas about the ways that students could outwardly demonstrate knowledge and understanding? What new possibilities did they suggest?

The results often surprised me. The students also demanded that I introduce new classroom practices, many of which I would not have chosen left to my own devices. For example, many students preferred exchanging ideas about assigned readings in small groups before moving to full-group, student-led discussion. This made me uncomfortable because I could not possibly hear every conversation as I could in full-class activities. But I was reminded 
that I do not need to personally witness or formally measure every instance of growth. I need to create the conditions that make this possible and then foster long-term individual patterns of change.

The interview process held both my students and me accountable. By listening and making changes to how learning happens, I valued student agency as integral to the learning process. As a result, we are all deeply invested in the value of these activities. One student opened up about her fears and concerns about reading and writing and her level of engagement in the course profoundly changed after her interview. She commented, "Before the learning interview, I was not confident enough to participate in class discussions to voice my opinions." We have moved as a group toward what Black and Wiliam (1998) call "a classroom culture of questioning and deep thinking in which pupils will learn from shared discussions with teachers and from one another” (p. 146) and the interviews supported this change.

\section{Concluding Thoughts From Craig}

I have come to appreciate that almost all of the great learning I have witnessed or experience has occurred in the context of relationship. No longer do I aspire to be a witty, wellinformed, and likeable teacher who can hold student attention for 85 minutes through "edutainment," as an enjoyable but nonetheless privileged voice at the front of the room. Instead, I struggle every day to solve the problem of creating the conditions for student agency. This has required hard work, risk-taking, and an abandonment of well-entrenched daily practices. It has meant new ways of relating to students. As I struggle to create the conditions for growth, students are invited into activities in which they seek to create meaning together out of the literature we study.

While much of my own professional growth came in the area of formative assessment and the need for greater student agency, it was the process of self-study that has led me to be aware of the need for these changes. And these changes could only have occurred in a supported environment. I am reminded of Black and Atkin's (1996, as cited in Black \& Wiliam, 1998) idea that meaningful professional change can only happen relatively slowly, and through sustained programmes of professional development and support (p. 10). Ann and Sherry's role has not been limited to a single seminar, workshop, set of meetings, classroom observation, or a conference. It has included all of these elements over the course of several years as part of a sustained relationship between our organizations.

\section{Continuous Openness to Transformation-Sherry and Ann}

How might an investment of time, space, and critical dialogue, what Moss (2014) and Dahlberg and Lenz Taguchi (1994) describe as “meeting places," invigorate localized professional growth and participation? How might such meeting places allow us to trouble dominating discourses that govern our local theories, beliefs, practices, and products? How might self-study or teachers' exploration of situations, experiences, and stories invite and/or support educators' efforts to construct and examine their own practices in conscientious, principled, and judicious ways. How might self-study bring together belief and action (Cole \& Knowles, 1996)?

As the university partners, we (Sherry and Ann) gave a great deal of encouragement and feedback, but so did Craig's teaching colleagues. He writes that he feels the having responsibility and control of his own learning has expanded through this process of self-study. Craig's work 
thoughtfully speaks to the effects of our collective attempts to organize ourselves with and amongst others, including the other that is our self, through critical, affirmative, conversations over a sustained period. Our conversations spiralled up and down, back and forth, through a range of unfolding practical inquiries about teaching and learning. As learners, we moved in and out of conversation with Craig, his colleagues, and the many researchers we met and read, and with whom we worked to examine ideas like formative assessment as a resource for learning about teaching and learning. Critical to this work is an open acceptance to go where both our collective conversations and individual learnings take us. We continue to reside in the transformative spaces as we reflect upon and analyze learning environments, relationships while troubling normed classroom procedures.

Through these actions, Craig has seen a distinct change in the ways the authority of the classroom has been shared. We drew on the notion of shared authority described by Frisch (1990) when he talks of the "authorship of a final narrative." The ownership of processes in the classroom become shared through this pedagogy of formative assessment, calling on students to become responsible, responsive, and autonomous. Sitzia (2003) describes her own work saying that she found the process of developing shared authority to be exciting, stimulating and resulting in a successful collaboration in much the same way Craig described his experiences. Although thinking about shared authority was not the initial intention in Craig's work, the learning communities in his classes became ones that exhibited the characteristics of what Basu and Calabrese-Barton (2010) described as opportunities for student voices being shared, joint decisions being made about what was taught and how it was taught, choices in assignments and assessment strategies being offered. They also describe the recognition of the students' funds of knowledge being brought into the curriculum in much the same way Craig described. This work also reminds us of the work of Giroux (1997) when he described the idea of what Thayer-Bacon (2006) later called "community-in-the-making" where authority always represents a terrain of struggle. Craig certainly found this to be the case initially and only later in the year did he find he was able to feel more confidence and less tension as the community of learners evolved.

As we reflected individually with Craig, a range of diverse questions unfolded. Craig's work addresses several of these. For example, the challenge of how to achieve student agency recognizes that agency is a necessary condition for learning, for self-study, and for community. As we travel in and out of each other's spaces, experiences and questions, we challenge ourselves, our pedagogies, and in the presence of others, call into question some of our pedagogic commitments and the distractions of curriculum guides, course syllabi and normed assessment practices. Increasingly we continue to be self-critical about imposing our understandings and learnings as a way to teach, opening up spaces for learners of all ages to call forward and reflect upon and question their experiences with one another. The act of self-study enhances this process and is focused in these practices.

As Craig discovered through his self-study, "We need to wait our turn.” Resisting the temptation to teach is key in learning contexts as we move to create spaces for learners' experiences, voices, and meaning making. Resisting the temptation to dominate teaching and assessment opens up spaces where students and teachers can consciously examine their actions to align them with their beliefs and goals in the presence of each other's thinking (Pinnegar, Hamilton, \& Fitzgerald, 2010, p. 235). 
The processes in self-study have uncovered many things for Craig and the others he works with. The focus on self has highlighted that classes and meeting spaces shaped by learner generated questions or learner generated desires are not easily achieved, if ever achieved in a completed sense. There are relational and ethical tensions and complexities revealed through self-study, as well as temporal, curricular, and assessment pressures that need to be continually negotiated.

Through the processes evolving in this colleague supported self-study, we recognize that we need to continue to work to co-construct classroom environments that value dispositions of playfulness - to experiment as a form of problem solving; performance - to adopt alternative identities and perspectives, collective intelligence - to pool knowledge as we work towards common goals, negotiation-to travel across diverse communities, discerning and respecting multiple perspectives and grasping and following alternative norms. Jenkins (2009) describes these as some of the characteristics of participatory cultures, and suggests that creativity is also essential to self-study for both "students as teachers" and "teachers as students." As Craig critically reflects, it is difficult when working alone.

When educators become learners and students becomes educators, the autonomous hierarchical position of the individualized educator dissolves. It further dissolves when we, as educators, collectively commit time, space, and critical dialogue to theorizing about our teaching practices so that application and significance can be debated (Grumet, 2009). As active participants, we continue to openly unpack the naturalness of "doing" education realizing that pedagogy should "not to be the prisoner of too much certainty, but instead be aware of both the relativity of its power and the difficulties of translating its ideals into practice” (Malaguzzi, 1995, p. 52).

Pinar (2005) writes:

Educational experience that is subjectively meaningful and socially significant does not occur readily through curriculum connected to standardized examinations. Especially in the nightmare that is the present, "the 'sweaty fight for meaning and response-ability' is an always-new struggle.... It's difficult, challenging, exhilarating, discouraging, numbing, mandatory, and exciting work - daily work that's always in-the-making. (p. xxii)

Critical to the work we undertook together and individually were on-going attempts to reflect upon and analyze learning environments, learning relationships, and "normed" classroom procedures. Critical contradictory moments are encounters steeped in power inequities, moments that trouble educational common sense, moments where we can make our educational practices strange, where we step outside of them temporarily to imagine new possibilities. Mining these moments through self-study becomes a space for investigating the complexities and ambiguities of learning to teaching. As Lenz Taguchi (2007) states, “an ethic of 'resistance,' affirmation, and becoming starts by performing deconstructive processes on your everyday practice; not to correct it towards a visionary or universally good end state, but, to facilitate a process of becoming" (Lenz Taguchi, 2007, p. 288) only to become again and again and again. 


\section{References}

$\mathrm{Au}, \mathrm{W}$. (2009). Social studies, Social justice: W(h)ither the social studies in high-stakes testing? Teacher Education Quarterly, Winter, 43-58.

Basu, S. J., \& Calebrese Barton, A. (2010). A researcher-student-teacher model for democratic science pedagogy: Connections to community, shared authority, and critical science agency. Equity and Excellence in Education, 43(1), 72-87.

Berry, A. (2007) Reconceptualizing teacher educator knowledge as tensions: Exploring the tension between valuing and reconstructing experience. Studying Teacher Education, 3(2), 117-134.

Black, P., \& Wiliam, D. (1998). Inside the black box: Raising standards for classroom assessment. Phi Delta Kappan, 80(2), 139-148. Retrieved from http://www.michigan.gov/documents/mde/Inside_the_Black_Box_184495_7.pdf

Boyce, M., (1996). Teaching critically as an act of praxis and resistance. Electronic Journal of Radical Organization Theory, 2(2). Retrieved from http://www.mngt.waikato.ac.nz/ejrot/Vol2_2/boyce.pdf

Britzman, D. P. (2012). Practices makes practice: A critical study of learning to teach, (Revised ed.). New York, NY: SUNY Press

Bullough Jr. R. \& Pinnegar, S. E. (2004). Thinking about the thinking about self-studies: An analysis of the first eight chapters. International Handbook of Self-Study of Teaching and Teacher Education Practices. Springer International Handbooks of Education, 12, 313342.

Cole, A., \& Knowles, G. (1996). The politics of epistemology and the self-study of teacher education practices, OISE. Paper presented at the First International Conference on SelfStudy of Teacher Education Practices, Herstmonceux Castle, East Sussex, England.

Davies, A., Herbst, S., \& Parrot-Reynolds, B. (2012). Leading the way to assessment for learning: A practical guide. Courtenay, $\mathrm{BC}$ : Connections.

Dahlberg, G., \& Lenz Taguchi, H. (1994). Preschool and school: Two different traditions and the vision of a meeting-place. Stockholm, SE: HLS Förlag.

Day, C. (1999). Developing teachers: The challenges of lifelong learning. New York, NY: Psychology Press. Frisch

Frisch, M. (1990). A shared authority: Essays on the craft and meaning of oral and public history. Albany, NY: State University of New York Press.

Giroux, H. (1997). Pedagogy and the politics of hope: Theory, culture and schooling, Boulder, CO: Westview Press.

Grumet, M. (2009). Curriculum inquiry, theory and politics. Curriculum Inquiry, 39(1), 221-234.

Hamilton, M. L. (1996). Reconceptualizing teacher education: Self-study. Teacher education. New York, NY:Psychology Press. 
Herbst, S. (2014, April). Where to from here? What's next for assessment for learning? Notes from an Assessment for Learning: Canada in Conversation with the World lecture conducted at University of New Brunswick., Fredericton, NB.

Jenkins, H. (2009). Confronting the challenges of participatory cultures: Media education for the 21st century. Cambridge, MA: MIT Press

Kellner, D., (2003). Toward a critical theory of education. Democracy and Nature: The International Journal of Inclusive Democracy, 9(1). Retrieved from http://pages.gseis.ucla.edu/faculty/kellner/essays/towardcriticaltheoryofed.pdf

Lenz Taguchi, H. (2007). Deconstructing and transgressing the theory-practice dichotomy in early childhood education. Educational Philosophy and Theory, 39(3), 275-290.

Loughran. J. J. (2004). Learning through self-study: The influence of purpose, participants and context. International Handbook of Self-Study of Teaching and Teacher Education Practices. Springer International Handbooks of Education, 12, 151-192.

Malaguzzi, L. (1995). Your image of the child: Where teaching begins, Child Care Exchange, 96, 52-61.

Moss, P. (2014). Early childhood and compulsory education: Reconceptualising the relationship. New York, NY: Routledge.

Pignatelli, F (2005). Student Resistance and Standardization in Schools. Rethinking Resistance in Schools: Power, Politics and Illicit Pleasures. May, 50-61.

Pinar, W. F. (2005). Preface: What should be and what might be. In J. L. Miller, Sounds of silence breaking: Women, autobiography, and curriculum. New York, NY: Peter Lang.

Pinar, W. F. (2006). Foreword: The lure that pulls flowerheads to face the sun. In D. Jardine, S. Friesen, \& P. Clifford, Curriculum in abundance. Mahwah, NJ: Laurence Erlbaum.

Pinnegar, S., Hamilton, M. L., \& Fitzgerald, L. (2010) Guidance in being and becoming selfstudy of practice researchers. In. L. Erickson, J. Young, \& S. Pinnegar. (2010). Proceedings of the eighth international conference on self-studies of teacher education practices: Navigating the public and the private: Negotiating the diverse landscapes of teacher education (pp.203-206). Herstmonceaux Castle UK: Self-Study of Teacher Education Practices SIG.

Samaras, A. P. (2002). Self-study for teacher educators: Crafting a pedagogy for educational change, New York, NY: Peter Lang Press.

Schon, D, (1983). The reflective practitioner: How practitioners think in action. New York, NY. Basic Books.

Sitzia, L. (2003). A shared authority: An impossible goal? The Oral History Review, 30(1), 87101.

Thayer-Bacon, B. J. (2006). Shared authority in democratic classrooms: Communities-always-inthe-making. In K. Cooper \& R. White (Eds.), The practical critical education(pp. 95109). Dordrecht, NL: Springer. 
Wiliam, D. (2011). Embedded formative assessment. Bloomington, IN: Solution Tree Press. 